\title{
Prevalence of post-stroke anxiety and its association with socio-demographical factors, post-stroke depression, and disability
}

Ankita V. Patel ${ }^{1,2}$, Shanaya H. Shah², Kamlesh Patel'2, Prakash I. Mehta ${ }^{1}$, Naren Amin'², Chetan Shah², Sanjiv H. Prajapati, 3

${ }^{1}$ GMERS Medical College and Hospital, Sola, Ahmedabad, Gujarat, India

${ }^{2}$ C.U. Shah Medical College, Surendranagar, Gujarat, India

${ }^{3}$ Diplomate of National Board Cardiology, Apollo Hospital, Bangalore, India

Neuropsychiatria i Neuropsychologia 2018; 13, 2: 43-49

Address for correspondence:

Dr Ankita V. Patel

GMERS Medical College and Hospital, Sola

382481 Ahmedabad, Gujarat, India

e-mail: avevenstar@gmail.com

\section{Abstract}

Introduction: Anxiety is the most common mental health problem worldwide. It can compromise rehabilitation outcome and negatively impact the quality of life after stroke.

Aim of the study: The aim of this study was: 1) to determine the prevalence of post-stroke anxiety (PSA), 2) to study PSA and its association with socio-demographical factors, and 3) to study PSA and its association with post-stroke depression (PSD) and disability.

Material and methods: One hundred consecutive patients with clinical diagnosis of stroke were included in the study. Detailed socio-demographic and other variables and psychiatric history were obtained using a semi-structured Performa. Subjects were given HAM-A, HAM-D, and WHODAS 2.0 to assess anxiety, depression, and disability, respectively. Descriptive statistics were used to determine the socio-demographical variables. Chi square test and Fisher exact test were used to find the significance of study parameters on a categorical scale between two or more groups.

Results: Of 100 patients, 35 were anxious. Socio-economic deprivation was significantly associated with PSA. Illiteracy was nearly significantly associated with PSA. No co-morbidities, number of strokes, and substance use were significantly associated with PSA. PSA is significantly associated with PSD. The correlation between severity of PSA and PSD was found to be highly significant. PSA is not significantly associated with post-stroke disability. Conclusions: PSA is highly prevalent in post-stroke patients, and it has been significantly associated with socio-economic deprivation, illiteracy, and PSD. We need to screen post-stroke subjects for anxiety and other modifiable variables associated with it, in order to provide an effective management plan.

Key words: anxiety, depression, disability, stroke.

\section{Introduction}

Anxiety is the most common mental health problem worldwide (Lepine 2002), with an estimated lifetime prevalence of approximately $11 \%$ (Kessler et al. 2009). Common behavioural and cognitive consequences of stroke include depression, psychosis, apathy, anxiety, personality change, aphasia, and dysprosody. Depression and anxiety are the most common emotional disturbances after stroke (Hackett et al. 2014). In different studies, the prevalence of post-stroke anxiety (PSA) ranged from $4 \%$ to $28 \%$ (Astrom 1996; House et al. 1991).
In terms of disability, as per the Lancet $28 \mathrm{Nov}$ 2009 issue, stroke is found to be the leading cause worldwide, and in developing countries it is the second leading cause of disability (Gopi et al. 2017).

Anxiety can compromise rehabilitation outcome and negatively impact the quality of life after stroke. It may affect daily functioning, quality of life, relationships, and functional outcome (Astrom 1996; Carod-Artal and Egido 2009; Ferro et al. 2009; West et al. 2010).

Co-morbidity of PSA and post-stroke depression (PSD) is high, with as many as $85 \%$ 
of people with generalised anxiety having co-morbid depression during the three years post stroke (Castillo et al. 1995; Castillo et al. 1993).

Emotional problems may lead to a complicated clinical presentation, poor response to treatment, and sometimes unnecessary investigations. Emotional disturbances influence stroke patient recovery of motor and cognitive deficits as well as the mortality risk associated with stroke (Shimoda and Robinson 1998; Simon et al. 1995; Lewis et al. 2001).

Because of paucity of literature on PSA, the prognosis of patients with PSA is also poorly understood because it remains unknown whether PSA is associated with other health-related outcomes such as mortality, disability, recurrence of stroke, cognitive impairment, or lower quality of life (Campbell et al. 2013; Wolfe et al. 2011).

In order to develop effective management of post-stroke emotional disturbances we need to identify the prevalence of PSA and modifiable variables associated with it, which could provide targets for early intervention and treatment.

There is a paucity of data in this area of research from India. In this study, we aimed to assess the prevalence of PSA and its association with socio-demographic factors, PSD, and disability.

\section{Aim of the study}

The aim of this study was:

1) to determine the presence of PSA,

2) to study PSA and its association with sociodemographical factors,

3) to study PSA and its association with PSD and post-stroke disability.

\section{Material and methods}

This cross-sectional observational study was conducted at the tertiary care hospital of Surendranagar district of Gujarat state, India, during August 2015 to January 2016. The study was approved by the Institutional Ethical Committee.

One hundred consecutive patients with clinical diagnosis of stroke (haemorrhagic or ischaemic), who gave informed consent, were included in the study. Patients with aphasia, acute confusional state, altered sensorium, history of psychiatric illness before and at the time of stroke, significant cognitive disturbances, and duration since onset of stroke less than one month were excluded from the study.

The socio-demographical data and clinical variables were recorded in a specific Performa prepared for this clinical study. Detailed history about number of stroke, co-morbidities (particularly hypertension, diabetes, and thyroid dysfunction), substance use, and past history of any psychiatry illness was evaluated. All the patients underwent a thorough clinical and psychiatric examination. Anxiety, depression, and disability were assessed using the following scales:

- Hamilton Rating scale for Anxiety (HAM-A; Hamilton 1959): HAM-A is a widely used and well-validated tool for measuring the severity of a patient's anxiety. Each item is scored on a five-point scale, ranging from $0=$ not present to $4=$ severe. The scores from all 14 parameters are summed: $0-13=$ normal, $14-17=$ mild anxiety, $18-24=$ moderate anxiety, and $25-30=$ severe anxiety.

- Hamilton Rating scale for Depression (HAM-D; Hamilton 1960): HAM-D has proven useful for many years as a way of determining a patient's level of depression before, during, and after treatment. Eight items are scored on a five-point scale, ranging from $0=$ not present to $4=$ severe. And nine are scored from $0-2$. The scores are summed from the first 17 items: $0-7=$ normal, 8-13 = mild depression, $14-18=$ moderate depression, $19-22=$ severe depression, $\geq 23$ = very severe depression.

- World Health Organisation Disability Assessment Schedule (WHODAS 2.0; ): WHODAS 2.0 covers six domains of functioning, including cognition, mobility, self-care, getting along, life activities, and participation. The more complex method of scoring is called "item-response-theory" (IRT)-based scoring. It takes into account multiple levels of difficulty for each WHODAS 2.0 item. It takes the coding for each item response as "none", "mild", "moderate", "severe", and "extreme" separately, and then uses an algorithm to determine the summary score by differentially weighting the items and the levels of severity. The SPSS algorithm is available from the WHO. The scoring has three steps:

- step 1 - summing of recoded item scores within each domain,

- step 2 - summing of all six domain scores,

- step 3-converting the summary score into a metric ranging from 0 to 100 (where $0=$ no disability, $100=$ full disability): $0-4 \%$ $=$ no problem, $5-24 \%=$ mild problem, $25-49 \%=$ moderate problem, $50-95 \%$ $=$ severe problem, $96-100 \%=$ complete problem.

Descriptive statistics were used to determine the socio-demographic and other variables. 
$\chi^{2}$ test was used to find the significance of study parameters on a categorical scale between two or more groups, and where we were not able to apply $\chi^{2}$ test, we applied the Fisher exact test ( $p$-value was set at less than or equal to 0.05$)$. Collected data were analysed using SPSS version 16 .

\section{Results}

One hundred patients were included in this study. Of 100 patients, 35 were anxious $(35 \%)$ and 65 were non-anxious (65\%). Among the 35 anxious patients, 13 had mild (13\%), 17 had moderate $(17 \%)$, and five had severe (5\%) anxiety (Table 1).

Socio-economic deprivation was significantly associated with PSA. Also, variable like illiteracy was nearly significantly associated with PSA. The majority of patients belonged to one religion,
Table 1. Prevalence of post-stroke anxiety

\begin{tabular}{lc}
\hline Total $(n)$ & 100 \\
\hline Not anxious & 65 \\
\hline Mildly anxious & 13 \\
\hline Moderately anxious & 17 \\
\hline Severely anxious & 5 \\
\hline
\end{tabular}

so there can be falsification in this observation of association between religion and PSA. Other socio-demographical variables were not significantly associated with PSA (Table 2).

No co-morbidities, number of strokes, and substance use were factors significantly associated with PSA (Table 3).

PSA is significantly associated with post-stroke depression (Table 4). The correlation between

Table 2. Correlation between socio-demographic variables and post-stroke anxiety

\begin{tabular}{|c|c|c|c|c|c|c|c|}
\hline \multicolumn{2}{|c|}{ Socio-demographic variables } & \multirow{2}{*}{$\begin{array}{c}\text { Anxious (\%) } \\
1(2.86)\end{array}$} & \multirow{2}{*}{$\begin{array}{c}\text { Not anxious (\%) } \\
1(1.54)\end{array}$} & \multirow{2}{*}{$\begin{array}{c}\text { Total } \\
2\end{array}$} & \multirow{2}{*}{$\begin{array}{c}\chi^{2} \\
5.259\end{array}$} & \multirow{2}{*}{$d f$} & \multirow{2}{*}{$\begin{array}{r}p \text {-value } \\
0.385\end{array}$} \\
\hline Age & $21-30$ & & & & & & \\
\hline & $31-40$ & $1(2.86)$ & $6(9.23)$ & 7 & & & \\
\hline & $41-50$ & $12(34.28)$ & $17(26.15)$ & 29 & & & \\
\hline & $51-60$ & $11(31.43)$ & $24(36.92)$ & 35 & & & \\
\hline & $61-70$ & $6(17.14)$ & $15(23.08)$ & 21 & & & \\
\hline & $71-80$ & $4(11.43)$ & $2(3.08)$ & 6 & & & \\
\hline \multirow[t]{2}{*}{ Sex } & Male & $26(74.29)$ & $47(72.31)$ & 73 & 0.045 & 1 & 0.832 \\
\hline & Female & $9(25.71)$ & $18(27.69)$ & 27 & & & \\
\hline \multirow[t]{2}{*}{ Religion } & Hindu & $35(100)$ & $57(87.69)$ & 92 & 4.682 & 1 & 0.030 \\
\hline & Muslim & 0 & $8(12.31)$ & 8 & & & \\
\hline \multirow[t]{2}{*}{ Residence } & Rural & $26(74.29)$ & $47(72.31)$ & 73 & 0.045 & 1 & 0.832 \\
\hline & Urban & $9(25.71)$ & $18(27.69)$ & 27 & & & \\
\hline \multirow[t]{2}{*}{ Education } & Literate & $15(42.86)$ & $40(61.54)$ & 55 & 3.208 & 1 & 0.073 \\
\hline & Illiterate & $20(57.14)$ & $25(38.46)$ & 45 & & & \\
\hline \multirow[t]{4}{*}{ Occupation } & Unemployed & $24(68.57)$ & $46(70.77)$ & 70 & 1.518 & 3 & 0.678 \\
\hline & Inconsistent earning & $7(20)$ & $8(12.31)$ & 15 & & & \\
\hline & $\begin{array}{l}\text { Consistent monthly } \\
\text { pay but not perma- } \\
\text { nent }\end{array}$ & $3(8.57)$ & $7(10.77)$ & 10 & & & \\
\hline & Permanent pay & $1(2.86)$ & $4(6.15)$ & 5 & & & \\
\hline \multirow[t]{3}{*}{ Marital status } & Single & $2(5.72)$ & $1(1.54)$ & 3 & 1.442 & 2 & 0.486 \\
\hline & Married & $30(85.71)$ & $57(87.69)$ & 87 & & & \\
\hline & Widow & $3(8.57)$ & $7(10.77)$ & 10 & & & \\
\hline \multirow[t]{2}{*}{ Family type } & Joint & $12(34.29)$ & $29(44.62)$ & 41 & 1.004 & 1 & 0.316 \\
\hline & Nuclear & $23(65.71)$ & $36(55.38)$ & 59 & & & \\
\hline \multirow{5}{*}{$\begin{array}{l}\text { Socio-economical } \\
\text { class }\end{array}$} & I & 0 & $9(13.85)$ & 9 & 17.992 & 4 & 0.001 \\
\hline & II & $8(22.86)$ & $5(7.69)$ & 13 & & & \\
\hline & III & $4(11.42)$ & $25(38.46)$ & 29 & & & \\
\hline & IV & $15(42.86)$ & $15(23.08)$ & 30 & & & \\
\hline & V & $8(22.86)$ & $11(16.92)$ & 19 & & & \\
\hline
\end{tabular}


Table 3. Correlation between stroke-related variables and post-stroke anxiety

\begin{tabular}{|c|c|c|c|c|c|c|c|}
\hline \multicolumn{2}{|c|}{ Stroke related variables } & \multirow{2}{*}{$\begin{array}{c}\text { Anxious (\%) } \\
29(82.86)\end{array}$} & \multirow{2}{*}{$\begin{array}{c}\text { Not anxious (\%) } \\
54(83.08)\end{array}$} & \multirow{2}{*}{$\begin{array}{c}\text { Total } \\
83\end{array}$} & \multirow{2}{*}{$\begin{array}{c}\chi^{2} \\
0.0008\end{array}$} & \multirow{2}{*}{$\begin{array}{c}d f \\
1\end{array}$} & \multirow{2}{*}{$\begin{array}{r}p \text {-value } \\
0.978\end{array}$} \\
\hline Number of strokes & First stroke & & & & & & \\
\hline & Recurrent stroke & $6(17.14)$ & $11(16.92)$ & 17 & & & \\
\hline \multirow[t]{2}{*}{ Substance use } & Absent & $12(34.29)$ & $29(44.62)$ & 41 & 1.004 & 1 & 0.316 \\
\hline & Present & $23(65.71)$ & $36(55.38)$ & 59 & & & \\
\hline \multirow{2}{*}{$\begin{array}{l}\text { Co-morbidities } \\
\text { (hypertension, dia- } \\
\text { betes, and thyroid } \\
\text { dysfunction) }\end{array}$} & Absent & $14(40)$ & $24(36.92)$ & 38 & 0.091 & 1 & 0.762 \\
\hline & Present & $21(60)$ & $41(63.08)$ & 62 & & & \\
\hline
\end{tabular}

Table 4. Correlation between post-stroke anxiety and depression

\begin{tabular}{lccc} 
Variables & $\begin{array}{c}\text { Anxious (\%) } \\
\text { (HAM-A } \geq 14)\end{array}$ & $\begin{array}{c}\text { Not anxious (\%) } \\
\text { (HAM-A < 14) }\end{array}$ & $\begin{array}{c}\text { Fisher exact test statistic } \\
\text { value* }\end{array}$ \\
$\begin{array}{l}\text { Not depressed (\%) } \\
\text { HAM-D }<8)\end{array}$ & 0 & $31(47.69)$ & $<0.00001$ \\
\hline $\begin{array}{l}\text { Depressed (\%) } \\
\text { HAM-D } \geq 8)\end{array}$ & $35(100)$ & $34(52.31)$ \\
\hline Total $(\%)$ & $35(100)$ & $65(100)$ \\
\hline
\end{tabular}

* The result is significant at $p$-value $<0.05$

Table 5. Correlation of severity of post-stroke anxiety and post-stroke depression

\begin{tabular}{|c|c|c|c|c|c|c|}
\hline \multirow[t]{2}{*}{ Variables } & & \multicolumn{4}{|c|}{ Anxiety } & \multirow{7}{*}{$\begin{array}{c}\chi^{2}=90.747 \\
d f=12 \\
p \text {-value }<0.0001\end{array}$} \\
\hline & & Not anxious & Mild & Moderate & Severe & \\
\hline \multirow[t]{5}{*}{ Depression } & Not depressed & 31 & 0 & 0 & 0 & \\
\hline & Mild & 23 & 1 & 0 & 0 & \\
\hline & Moderate & 10 & 4 & 3 & 0 & \\
\hline & Severe & 1 & 6 & 5 & 1 & \\
\hline & Very severe & 0 & 2 & 9 & 4 & \\
\hline
\end{tabular}

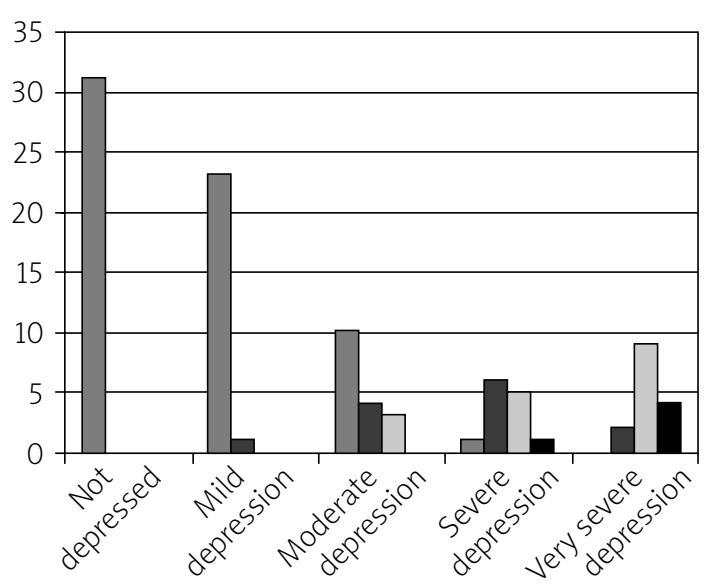

$\square$ Not anxious $\square$ Moderate anxious

Mild anxious

- Severe anxious

Fig. 1. Correlation of severity of post-stroke anxiety and post-stroke depression

severity of PSA and PSD was found to be highly significant (Table 5 and Fig. 1).
PSA is not significantly associated with post-stroke disability (Table 6). The correlation between severity of PSA and disability was found to be not significant (Table 7 and Fig. 2).

\section{Discussion}

We examined the prevalence of PSA and its association with socio-demographical and other variables, PSD, and post-stroke disability.

In our study, the prevalence of PSA was found to be $35 \%$. A recent systemic review by Campbell et al. (2013) reported that approximately $20-25 \%$ of patients have PSA at any time after stroke, with a $25 \%$ prevalence in studies using scales and $18 \%$ in studies using clinical interviews. Astrom et al. (1996) and House et al. (1991) reported a prevalence of PSA ranging from $4 \%$ to $28 \%$. A study by Barker-Collo (2007) reported a prevalence of mild anxiety of 
Table 6. Correlation between post-stroke anxiety and disability

\begin{tabular}{lccc} 
Variables & $\begin{array}{c}\text { Anxious (\%) } \\
\text { (HAM-A } \geq 14)\end{array}$ & $\begin{array}{c}\text { Not anxious (\%) } \\
\text { (HAM-A < 14) }\end{array}$ & $\begin{array}{c}\text { Fisher exact test statistic } \\
\text { value* }\end{array}$ \\
\cline { 1 - 3 } No disability (\%) & 0 & $03(4.62)$ & 0.5498 \\
\hline Disability (\%) & $35(100)$ & $62(95.38)$ & $65(100)$ \\
\hline Total (\%) & $35(100)$ & & \\
\hline
\end{tabular}

${ }^{*}$ The result is not significant at $p$-value $<0.05$

Table 7. Correlation of severity of post-stroke anxiety and disability

\begin{tabular}{|c|c|c|c|c|c|c|}
\hline \multirow[t]{2}{*}{ Variables } & & \multicolumn{4}{|c|}{ Anxious } & \multirow{6}{*}{$\begin{array}{c}\chi^{2}=14.168 \\
d f=9 \\
p \text {-value }=0.1165\end{array}$} \\
\hline & & Not anxious & Mild & Moderate & Severe & \\
\hline \multirow[t]{4}{*}{ Disability } & None & 3 & 0 & 0 & 0 & \\
\hline & Mild & 24 & 2 & 1 & 1 & \\
\hline & Moderate & 28 & 7 & 8 & 2 & \\
\hline & Severe & 10 & 4 & 8 & 2 & \\
\hline
\end{tabular}

$38.6 \%$, and a recent study by Ayerbe et al. (2014) reported a prevalence of PSA of over $30 \%$.

Our study population was hospital based, so the prevalence of PSA might be higher than in other rehabilitation- or community-based study populations. The difference in prevalence can be due to many factors like variation in assessment tools (rating scales or clinical interview), cut-off points for rating scales, and study area (hospital based, community based, or rehabilitation based).

Our study found a significant association between PSA and socio-economic class; PSA was more commonly seen in the socio-economically deprived group. A similar study reported by Broomfield et al. (2014) found significant association between PSA and socio-economic deprivation. Also, variable like illiteracy was nearly significantly associated with PSA. In the present study there was a significant association between PSA and religion, but the majority of patients belong to one religion, so there can be falsification in this observation.

In the present study, the association between PSA and socio-demographic factors like age, sex, residence, education, occupation, and type of family was not found to be significant. This is similar to the studies by Astrom et al. (1996), Barker et al. (2007), and Dennis et al. (2000), who reported no association between PSA and socio-demographic factors like age and sex. However, the study by Schultz et al. (1997) found that female and younger patients ( $<59$ years) are more susceptible to PSA.

Demographic factors play an important role in the development of PSA. Socio-economic de-

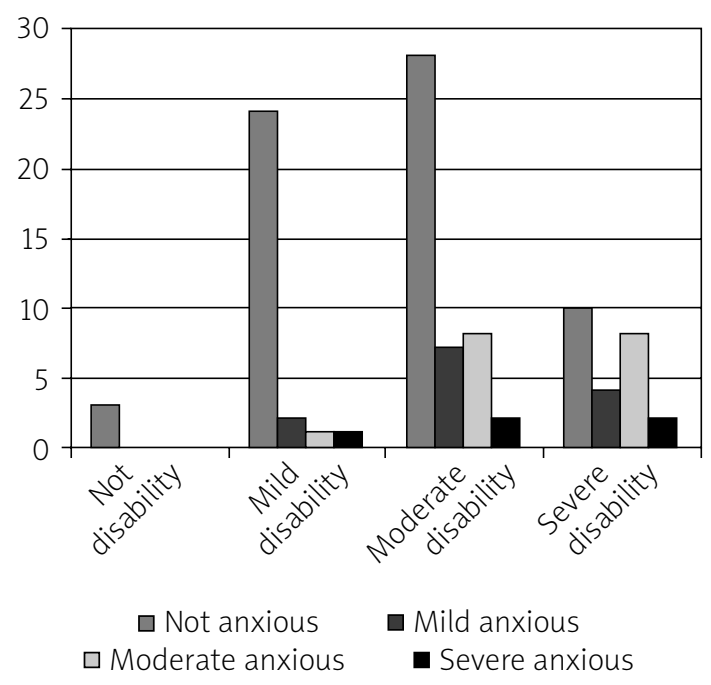

Fig. 2. Correlation of severity of post-stroke anxiety and disability

privation and illiteracy would hamper enrolment in rehabilitation programs, which may lead to long-term disability and emotional disturbances.

The association between PSA and number of strokes, substance use, and co-morbidities was not found to be significant in our study. For such variables, no similar studies were found.

Because of differing subject selection and methodological variations in different studies, comparison is difficult, and due to such limitations no significant conclusion could be reached.

In our study, PSA was significantly associated with PSD. Although there was a clear overlap between symptoms of anxiety and depression after stroke, correlation between severity of PSA and PSD was found to be highly significant in 
Table 8. Categorical analysis of laterality of lesion and site of lesion with post-stroke anxiety

\begin{tabular}{|c|c|c|c|c|}
\hline $\begin{array}{l}\text { Laterality of } \\
\text { lesion }\end{array}$ & Site of lesion & $\begin{array}{l}\text { Anxious (\%) } \\
(n=21)\end{array}$ & $\begin{array}{l}\text { Not anxious (\%) } \\
\quad(n=31)\end{array}$ & $\begin{array}{l}\text { Fisher's exact test } \\
\text { two-tailed } p \text {-value* }\end{array}$ \\
\hline \multirow[t]{3}{*}{ Right } & $C$ & $5(23.81)$ & $2(6.45)$ & 0.0629 \\
\hline & SC & 0 & $3(9.68)$ & \\
\hline & $C+S C$ & $1(4.76)$ & $4(12.90)$ & \\
\hline \multirow[t]{4}{*}{ Left } & $C$ & 3 (14.29) & $3(9.68)$ & 0.3068 \\
\hline & SC & $1(4.76)$ & $7(20.58)$ & \\
\hline & $C+S C$ & $4(19.05)$ & $4(12.90)$ & \\
\hline & Others & $1(4.76)$ & $1(3.23)$ & \\
\hline \multirow[t]{4}{*}{ Both } & C & $1(4.76)$ & $1(3.23)$ & 0.0618 \\
\hline & SC & 0 & $4(12.90)$ & \\
\hline & $C+S C$ & $3(14.29)$ & $2(6.45)$ & \\
\hline & Others & $2(9.52)$ & 0 & \\
\hline
\end{tabular}

C-cortical, SC-subcortical. * These groups are not significantly different

our study. Studies by Campbell et al. (2013), Leppavuori et al. (2003), Morrison et al. (2005), and Schultz et al. (1997) reported a positive association between PSD and PSA.

We found that PSA is not significantly associated with post-stroke disability. Also, correlation between severity of PSA and disability was found to be not significant. Similar results were observed in studies by Astrom et al. (1996), Sagen et al. (2010), and Starkstein et al. (1990), who found no association between PSA and activities of daily living. A study by Castillo et al. (1993; 1995) reported that PSA is not significantly correlated with physical functioning, cognitive functioning, or social functioning.

In patients with PSA, comorbidity with depression is also very high (Castillo et al. 1993). Studies found that depression is more severe and longer lasting in those with co-morbid anxiety, and patients with these comorbidities had higher levels of impairment of activities of daily living, higher cognitive impairment, and fewer social ties than those with depression alone (Shimoda and Robinson 1998). Hence, early treatment of anxiety could reduce the risk of subsequent depression and functional disability, and this may even improve their neurological disabilities and outcome in the long term.

PSA may reflect a more complex phenomenon than merely psycho-social factors, biological factors, or functional disability. Thus, by systemically studying all these contributing factors and their complex interactions, it gives us a greater understanding of these post-stroke psychological disturbances in their full context.
There were some limitations to our study, e.g. the sample size was small, the population of this study was not representative of the general population, and the exclusive criteria were specific. So, it is quite possible that excluded patients may have had anxiety and depression.

Although it was not mandatory for patients to bring brain imaging results, few patients brought such reports and hence their details were taken (Table 8). But because the sample size was small, the findings did not show much statistical significance and hence were not mentioned in the present study. Future studies with larger samples and correlation of post-stroke psychological disturbances to neurobiological, psychological, and socio-environmental factors altogether may provide more insight into this illness and its management plan.

\section{Conclusions}

The results of our study show that PSA is highly prevalent in post-stroke patients, and it has been significantly associated with factors like socio-economic deprivation, illiteracy, and PSD. It would provide us with greater insight into different modifiable variables associated with PSA and their interaction. We have to pay more attention to anxiety and depressive symptoms in post-stroke subjects for early identification and to treat them properly and on time. Anxiety can hamper stroke rehabilitation efforts and prevent patients from returning to their usual activities. Anxiety is a treatable condition, so efforts at early identification and treatment can have a positive impact on the rehabilitation process. 


\section{References}

1. Astrom M. Generalised anxiety disorder in stroke patients: A 3 year longitudinal study. Stroke 1996; 27: 270-275.

2. Ayerbe L, Ayis S, Crichton S, et al. Natural history, predictors and associated outcomes of anxiety up to 10 years after stroke: the South London Stroke Register. Age Ageing 2014; 43: 542-547.

3. Barker-Collo SL. Depression and anxiety 3 months post stroke: prevalence and correlates. Arch Clin Neuropsychol 2007; 22: 519-531.

4. Broomfield NM, Quinn TJ, Abdul-Rahim AH, et al. Depression and anxiety symptoms post-stroke/TIA: prevalence and associations in cross-sectional data from a regional stroke registry. BMC Neurol 2014; 14: 198.

5. Campbell Burton CA, Murray J, Holmes J, et al. Frequency of anxiety after stroke: a systematic review and meta-analysis of observational studies. Int J Stroke 2013; 8: 545-559.

6. Carod-Artal FJ, Egido JA. Quality of life after stroke: The importance of good recovery. Cerebrovasc Dis 2009; 27: 204-214.

7. Castillo CS, Schultz SK, Robinson R. Clinical correlates of early-onset and late-onset post stroke generalised anxiety. Am J Psychiatry 1995; 152: 1174-1181.

8. Castillo CS, Starkstein SE, Fedoroff JP, et al. Generalized anxiety disorder after stroke. J Nerv Ment Dis 1993; 181: 100-106.

9. Dennis M, O'Rourke S, Lewis S, et al. Emotional outcomes after stroke: Factors associated with poor outcome. J Neurol Neurosurg Psychiatry 2000; 68: 47-52.

10. Ferro JM, Caeiro L, Santos C. Post stroke emotional and behaviour impairment: A narrative review. Cerebrovasc Dis 2009; 27: 197-203.

11. Gopi S, Anbazhagan G, Balamurali K, et al. Prevalence and Severity of Post stroke depression and its relation with demographic and stroke characteristics. IOSR-JDMS 2017; 16: 12-17.

12. Hackett ML, Kohler S, O'Brien JT, et al. Neuropsychiatric outcomes of stroke. Lancet Neurol 2014; 13: 525-534.

13. Hamilton M. A rating scale for depression. J Neurol Neurosurg Psychiatry 1960; 23: 56.

14. Hamilton M. The assessment of anxiety states by rating. Br J Med Psychol 1959; 32: 50-55.

15. House A, Dennis M, Mogridge L, et al. Mood disorders in the year after first stroke. Br J Psychiatry 1991; 158: 83-92.

16. Kessler RC, Aguilar-Gaxiola S, Alonso J, et al. The global burden of mental disorders: an update from the WHO World Mental Health (WMH) surveys. Epidemiol Psichiatr Soc 2009; 18: 23-33.

17. Lepine JP. The epidemiology of anxiety disorders: prevalence and societal costs. J Clin Psychiatry 2002; 63 (Suppl 14): 4-8.

18. Leppavuori A, Pohjasvaara T, Vataja R, et al. generalized anxiety disorders three to four months after ischemic stroke. Cerebrovasc Dis 2003; 16: 257-264.

19. Lewis SC, Dennis MS, O'Rourke SJ, et al. Negative attitudes among short-term stroke survivors predict worse long-term survival. Stroke 2001; 32: 1640-1645.

20. Morrison V, Pollard B, Johnston M, et al. Anxiety and depression 3 years following stroke: Demographic, Clinical and psychological predictors. J Psychosom Res 2005; 59 : 209-213.

21. Sagen U, Finset A, Moum T, et al. Early detection of patients at risk for anxiety, depression and apathy after stroke. Gen Hosp Psychiatry 2010; 32: 80-85.
22. Schultz SK, Castillo CS, Kosier JT, et al. Generalized anxiety and depression: Assessment over 2 years after stroke. Am J Geriatr Psychiatry 1997; 5: 229-237.

23. Shimoda K, Robinson RG. Effects of anxiety disorder on impairment and recovery from stroke. J Neuropsychiatry Clin Neurosci 1998; 10: 34-40.

24. Simon G, VonKoroff M, Barlow W. Health care costs of patients with recognized depression. Arch Gen Psychiatry 1995; 52: 850-856.

25. Starkstein S, Cohen B, Fedoroff J, et al. Relationship between anxiety and depressive disorders in patients with cerebrovascular injury. Arch Gen Psychiatry 1990; 47: 246-251.

26. West R, Hill K, Hewison J, et al. Psychological disorders after stroke are an important influence on functional outcomes. A prospective cohort study. Stroke 2010; 41: 1723-1727.

27. World Health Organization. WHO Disability Assessment Schedule 2.0 (WHODAS 2.0). Available from: http://www. who.int/classifications/icf/whodasii/en/

28. Wolfe CD, Crichton SL, Heuschmann PU, et al. Estimates of outcomes up to ten years after stroke: Analyses from the prospective South London stroke register. PLoS Med 2011; 8: e1001033. 